\title{
EROSIVIDADE, PADRÕES HIDROLÓGICOS, PERÍODO DE RETORNO E PROBABILIDADE DE OCORRÊNCIA DAS CHUVAS EM SÃO BORJA, RS ${ }^{(1)}$
}

\author{
Elemar Antonino Cassol ${ }^{(2)}$, Flávio Luiz Foletto Eltz ${ }^{(3)}$, Daniela \\ Martins $^{(4)}$, Alexandra Minossi de Lemos ${ }^{(5)}$, Vladimir Silva de \\ Lima $^{(6)}$ \& Aristides Camara Bueno ${ }^{(7)}$
}

\begin{abstract}
RESUMO
A capacidade erosiva da chuva pode ser estimada utilizando-se de alguns índices, dentre os quais o mais utilizado é o $\mathrm{EI}_{30}$, que representa o produto da energia cinética de impacto das gotas da chuva (E) pela intensidade máxima de precipitação em $30 \mathrm{~min}\left(\mathrm{I}_{30}\right)$. O objetivo deste trabalho foi determinar a erosividade, os padrões hidrológicos, o período de retorno e a probabilidade de ocorrência das chuvas em São Borja, RS, com base no período de 1956 a 2003 . Foram utilizados pluviogramas diários da estação meteorológica da FEPAGRO, em São Borja, RS, a partir dos quais as chuvas individuais foram separadas em erosivas e não-erosivas. De cada chuva considerada erosiva foram cotados os segmentos de mesma inclinação, a hora e a quantidade acumulada, anotados em planilha, digitalizados e processados pelo programa computacional CHUVEROS, o qual calcula não só o índice $\mathrm{EI}_{30}$ da chuva e a erosividade mensal e anual, mas também determina os padrões hidrológicos de cada chuva. O período de outubro a abril concentrou $76 \%$ da erosividade anual, o que coincide com o preparo do solo, semeadura e crescimento das culturas de verão. O pico mais notável no potencial erosivo ocorreu em março e abril ( $\mathrm{EI}_{30}$ médio mensal de 1.260-1.269 $\mathrm{MJ} \mathrm{mm} \mathrm{ha}^{-1} \mathrm{~h}^{-1}$ ), quando,
\end{abstract}

(1) Trabalho realizado com apoio da FAPERGS. Recebido para publicação em março de 2007 e aprovado em fevereiro de 2008.

(2) Professor Associado, Departamento de Solos, Faculdade de Agronomia, Universidade Federal do Rio Grande do Sul - UFRGS. Av. Bento Gonçalves 7712, Caixa Postal 15100, CEP 91501-970 Porto Alegre (RS). E-mail: cassolea@orion.ufrgs.br

(3) Professor Titular, Depto de Solos, CCR, Universidade Federal de Santa Maria - UFSM. Campus Universitário, CEP 97105-900 Santa Maria (RS). Bolsista do CNPq. E-mail: feltz@ccr.ufsm.br

(4) Engenheira-Agrônoma, ex-bolsista de iniciação científica do CNPq. FA-UFRGS. E-mail: dmartins77@yahoo.com.br

(5) Estudante de graduação em Agronomia da UFRGS. Bolsista de iniciação científica da FAPERGS. E-mail: aleagro2001@yahoo.com.br

(6) Engenheiro-Agrônomo, Instituto Nacional de Colonização e Reforma Agrária - INCRA. Av. Loureiro da Silva 515, Porto Alegre (RS). E-mail: vladimir.Lima@poa.incra.gov.br

(7) Engenheiro-Agrônomo, Pesquisador da Fundação Estadual de Pesquisa Agropecuária - FEPAGRO. Porto Alegre (RS). Email: aristides.camara@fepagro.rs.gov.br 
normalmente, as culturas praticamente estão em pleno desenvolvimento, enquanto o menor potencial erosivo ocorreu em julho e agosto ( $\mathrm{EI}_{30}$ médio mensal de 268-271 MJ mm ha $\mathrm{m} \mathrm{h}^{-1}$ ). Do número total de chuvas erosivas, 47, 25 e $28 \%$ apresentaram padrões hidrológicos do tipo avançado, intermediário e atrasado, respectivamente, enquanto esses padrões perfizeram 50, 26 e $24 \%$ do volume médio anual de chuvas erosivas e 53, 25 e $22 \%$ da erosividade média anual das chuvas. $O$ valor do índice de erosividade anual para São Borja, RS, foi de $9.751 \mathrm{MJ} \mathrm{mm} \mathrm{ha-1} \mathrm{h}^{-1}$ $a^{-1}$ o qual representa o Fator "R" da Equação Universal de Perdas de Solo. A relação linear e potencial, que expressa o Fator " $R$ " da USLE, foi obtido de dados pluviométricos, representados pelo coeficiente de chuva, que pode ser utilizado para regiões climáticas semelhantes que apenas dispõem de dados pluviométricos.

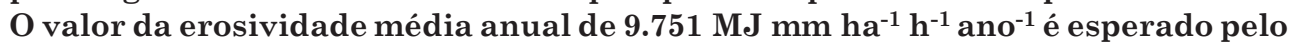
menos uma vez a cada 2,2 anos, com uma probabilidade de ocorrência de 44,9\%.

Termos de indexação: energia cinética, potencial erosivo da chuva, intensidade da chuva, fator "R" da USLE.

\title{
SUMMARY: EROSIVITY, HYDROLOGICAL PATTERNS, RETURN PERIOD AND PROBABILITY OF OCCURRENCE OF RAINFALLS AT SÃO BORJA, RS, BRAZIL
}

\begin{abstract}
The erosivity potential of rainfalls can be estimated by some indexes, among them the $E I_{30}$, which is given by the product of kinetic energy $(E)$ and rainfall intensity for a 30 minute period $\left(I_{30}\right)$. The purpose of this study was to determine rainfall erosivity, hydrological patterns, return period and probability of occurrence of erosive rainfalls in São Borja, RS, Brazil, based on diary rainfall charts of the FEPAGRO meteorological station, from 1956 to 2003. The duration and accumulated amount of each erosive rainfall were measured, entered in a spreadsheet, digitalized and processed by CHUVEROS software, which calculated the $\mathrm{EI}_{30}$ index and the monthly and annual total erosivity, besides determining the hydrological pattern of each rainfall. Most of the annual erosivity (76\%) was concentrated between October and April, in the period of soil tillage, sowing and growth of summer crops. The most notable peak in the erosive potential was observed between March and April (1,260-1,269 $\left.\mathrm{MJ} \mathrm{mm} \mathrm{ha}^{-1} \mathrm{~h}^{-1}\right)$, when most crops are normally in full growth, while July and August were the months of lowest erosive potential (268-271 MJ mm ha-1 $\left.\mathrm{h}^{-1}\right)$. Of the total erosive rainfalls 47, 25 and $28 \%$ had advanced, intermediary and delayed patterns, respectively, while these patterns corresponded to 50 , 26 and $24 \%$, respectively, of the mean annual volume of erosive rainfalls and to 53, 25 and $22 \%$ of the average annual erosivity. The mean annual index of erosivity in São Borja is 9,751 MJ mm ha ${ }^{-1} h^{-1}$ year-1. It represents the " $R$ " Factor of the Universal Soil Loss Equation to be used in São Borja and regions with similar rainfall pattern. Linear and potential regressions were obtained to express the mean annual $\mathrm{EI}_{30}$ index by pluviometric records expressed as rainfall coefficient. The mean anual rainfall erosivity index of $9,751 \mathrm{MJ} \mathrm{mm} \mathrm{ha}^{-1} \mathrm{~h}^{-1}$ year-1 (Factor " $R$ " of USLE for São Borja, RS, Brazil), is expected to occur once every 2.2 years, with a $44.9 \%$ likelihood.
\end{abstract}

Index terms: kinetic energy, rainfall erosive potential, rainfall intensity, USLE " $R$ " factor.

\section{INTRODUÇÃO}

A erosão hídrica do solo constitui grande problema nas áreas agrícolas. Além da redução da produtividade das culturas, pode causar sérios problemas ambientais, especialmente pelo assoreamento de rios e reservatórios e pela poluição dos recursos hídricos. Desde os trabalhos iniciais de Ellison (1946), sabe-se que o processo de erosão hídrica envolve a desagregação de partículas do solo da sua massa original, o transporte e a eventual deposição dessas partículas e que esse processo ocorre pela ação dos agentes erosivos, que são as gotas da chuva e o escoamento superficial da água sobre o solo. A erosão do solo é um processo mecânico que envolve energia. A energia necessária para desencadear o processo de erosão hídrica do solo é proveniente da água das chuvas e do escoamento 
superficial, especialmente a energia cinética do impacto das gotas de chuva sobre a superfície do solo. A capacidade potencial das chuvas em causar erosão do solo é denominada erosividade das chuvas. Perdas de solo por erosão hídrica podem ser estimadas pela aplicação de modelos de predição de erosão, sendo a Equação Universal de Perdas de Solo (USLE) (Wischmeier \& Smith, 1978) um dos modelos mais utilizados.

Wischmeier (1959) definiu o índice $\mathrm{EI}_{30}$ para determinação da erosividade das chuvas, tendo Wischmeier \& Smith (1978) utilizado esse índice para expressar o Fator "R" da USLE, o que foi dimensionado em unidades do sistema internacional por Foster et al. (1981). O índice $\mathrm{EI}_{30}$ representa o produto da energia cinética total da chuva $\left(\mathrm{MJ} \mathrm{ha}^{-1}\right)$ pela intensidade máxima $\left(\mathrm{mm} \mathrm{h}^{-1}\right)$ com base em período contínuo de 30 min de chuva. Morais et al. (1988) concluíram que o índice de erosividade $\mathrm{EI}_{30}$ é adequado para estimar o potencial erosivo das chuvas para o Rio Grande do Sul, baseado em correlações significativas obtidas entre esse índice de erosividade da chuva e as perdas de solo por erosão. Essa mesma conclusão foi obtida por vários pesquisadores em diferentes regiões edafoclimáticas brasileiras (Lombardi Neto, 1977; Marques et al., 1997; Albuquerque et al., 1998). Para a adequada utilização da USLE como modelo de predição de perdas de solo por erosão hídrica, é fundamental a determinação de seus parâmetros para as condições edafoclimáticas da região ou local onde será aplicada.

Para tanto é imprescindível a determinação do Fator "R" na respectiva região climática. Para determinação do Fator "R" da USLE, registros pluviográficos de períodos de chuva de 20 a 30 anos devem ser analisados.

A obtenção de dados de chuva com base em registros pluviográficos é um processo relativamente caro e a determinação da erosividade das chuvas a partir de pluviogramas diários é um procedimento moroso. De outra parte, a obtenção de dados de chuva com base em pluviometria é mais fácil e normalmente existe maior disponibilidade desses dados. Por essas razões, têm sido testadas relações da erosividade com a quantidade das chuvas. Muitos pesquisadores têm relacionado o coeficiente de chuva (Rc) com a erosividade das chuvas. O coeficiente de chuva expressa, para cada mês do ano, a relação entre o quadrado da precipitação média mensal $(\mathrm{Pm})$ e a média anual total $(\mathrm{Pa})$, isto é, $\mathrm{Rc}=\mathrm{Pm}^{2} / \mathrm{Pa}$. Carvalho et al. (1991), trabalhando com dados de Mococa, SP, e Roque et al. (2001), trabalhando com chuvas de Piraju, SP, obtiveram correlações potenciais altamente significativas entre o coeficiente de chuva e o índice de erosividade $\mathrm{EI}_{30}$. Por outro lado, relações lineares foram obtidas por Colodro et al. (2002) para as chuvas de Teodoro Sampaio, SP, com coeficiente de correlação de $r=0,963^{* *}$, e por Rufino et al. (1993), para oito regiões do Estado do Paraná, com coeficiente de correlação variando de $\mathrm{r}=0,84^{*}$ a $\mathrm{r}=0,93^{*}$. As relações obtidas podem ser empregadas em regiões climáticas semelhantes àquela onde foram determinadas, em locais que dispõem apenas de dados pluviométricos.

A estimativa dos períodos de retorno e da probabilidade de ocorrência da erosividade anual das chuvas possibilita estabelecer previsões da freqüência com que as predições de perdas de solo são sub ou superestimadas. Roque et al. (2001) determinaram que o Fator "R" da USLE para Piraju, SP, é de $7.074 \mathrm{MJ} \mathrm{mm} \mathrm{ha}^{-1} \mathrm{~h}^{-1} \mathrm{ano}^{-1}$ e que esse valor é esperado pelo menos uma vez a cada 2,33 anos, com uma probabilidade de ocorrência de 42,92\%. Os mesmos valores de período de retorno e probabilidade de ocorrência foram obtidos por Colodro et al. (2002), para Teodoro Sampaio, SP, onde o Fator "R" da USLE foi determinado em 7.172 $\mathrm{MJ} \mathrm{mm} \mathrm{ha}^{-1} \mathrm{~h}^{-1} \mathrm{ano}^{-1}$.

Além da erosividade, outra importante característica da chuva relacionada com o processo de erosão hídrica do solo é o padrão hidrológico. As chuvas foram caracterizadas por Horner \& Jens (1942) em padrões hidrológicos denominados avançado, intermediário e atrasado, os quais se caracterizam, respectivamente, quando a localização do pico de maior intensidade está no início (primeiro terço), meio (segundo terço) ou fim (terceiro terço) do período de duração da chuva. Sob idênticas condições de volume total, intensidade do pico e duração, as chuvas de padrão hidrológico atrasado são mais danosas do ponto de vista da erosão do solo, uma vez que o pico de intensidade ocorre no último terço do tempo de duração da chuva, quando o solo já se encontra com teor de umidade mais elevado. Mehl et al. (2001) caracterizaram os padrões de chuva em Santa Maria, $\mathrm{RS}$, e concluíram que o padrão avançado ocorre com maior freqüência.

Os objetivos do presente trabalho foram determinar a erosividade mensal e anual das chuvas pelo índice $\mathrm{EI}_{30}$, com base no período de 1956 a 2003 (48 anos de dados); estimar o valor do Fator "R" para utilização na Equação Universal de Perdas de Solo (USLE); determinar o padrão hidrológico, o período de retorno e a probabilidade de ocorrência das chuvas erosivas para a região de São Borja, RS.

\section{MATERIAL E MÉTODOS}

O município de São Borja localiza-se na parte oeste do Estado do Rio Grande do Sul, região fisiográfica das Missões, na fronteira do Brasil com a Argentina. Sua sede municipal está entre as coordenadas geográficas de latitude $28^{\circ} 39^{\prime} \mathrm{S}$ e longitude $56^{\circ} 00^{\prime} \mathrm{W}$ e altitude de $99 \mathrm{~m}$. No Centro de Pesquisa de Cereais da FEPAGRO, em São Borja, está localizada a estação agrometeorológica onde foram obtidos os pluviogramas diários. Foi determinado o índice $\mathrm{EI}_{30}$ para cada chuva individual e erosiva. De acordo com critérios sugeridos por Cabeda (1976), 
chuva individual é aquela separada da anterior e da posterior por um período mínimo de $6 \mathrm{~h}$ sem chuva ou com menos de $1,0 \mathrm{~mm}$ e chuva erosiva é toda aquela com quantidade igual ou superior a $10,0 \mathrm{~mm}$ ou com $6,0 \mathrm{~mm}$ ou mais desde que tenha ocorrido em $15 \mathrm{~min}$ ou menos. Foram analisadas 1.908 chuvas erosivas. No mesmo período, ocorreram também 1.964 chuvas não-erosivas.

Nos pluviogramas diários, as chuvas erosivas analisadas foram cotadas, identificando-se os segmentos com a mesma inclinação, os quais representam períodos de chuva com a mesma intensidade. Em planilhas, foram anotados a data da chuva e, para cada segmento uniforme de chuva, o tempo e a quantidade acumulada de chuva. Os dados levantados foram analisados pelo programa CHUVEROS, elaborado por Elemar Antonino Cassol (DS-FA-UFRGS), e as planilhas de cálculo Microsoft Office Excel, estimando-se a erosividade mensal, anual e média das chuvas, pelo índice $\mathrm{EI}_{30}$ (Wischmeier, 1959) dado no Sistema Internacional de Unidades (Foster et al., 1981). Para cada segmento uniforme de chuva foi determinada a energia cinética unitária, conforme a expressão de Wischmeier \& Smith (1978) que, em unidades do sistema internacional, é dada por:

$$
e=0,119+0,0873 \log _{10} i
$$

em que e representa a energia cinética unitária (MJ $\left.\mathrm{ha}^{-1} \mathrm{~mm}^{-1}\right)$ e $i$ é a intensidade da chuva $\left(\mathrm{mm} \mathrm{h}^{-1}\right)$ no segmento considerado. $\mathrm{O}$ valor obtido na expressão (1) é multiplicado pela quantidade de chuva no respectivo segmento uniforme, para expressar a energia cinética do segmento, em MJ ha ${ }^{-1}$. Somando a energia cinética de todos os segmentos uniformes de chuva, obtém-se a energia cinética total da chuva $\left(\mathrm{Ec}_{\mathrm{t}}\right)$.

A erosividade da chuva pelo índice $\mathrm{EI}_{30}$, é dada pela seguinte expressão:

$$
E I_{30}=E c_{t} I_{30}
$$

em que $E I_{30}$ é o índice de erosividade da chuva erosiva individual, em $\mathrm{MJ} \mathrm{mm} \mathrm{ha}{ }^{-1} \mathrm{~h}^{-1}, E c_{t}$ é a energia cinética total da chuva, em $\mathrm{MJ} \mathrm{ha}^{-1}$, e $I_{30}$ é a intensidade máxima da chuva em período contínuo de 30 min de chuva, em $\mathrm{mm} \mathrm{h}^{-1}$, ou seja, a quantidade máxima de chuva em um período contínuo de $30 \mathrm{~min}$ multiplicada por 2, determinada a partir dos dados levantados do pluviograma.

Somando os índices $\mathrm{EI}_{30}$ de todas as chuvas individuais e erosivas de cada mês, obteve-se a erosividade mensal das chuvas. Somando os índices $\mathrm{EI}_{30}$ mensais, obteve-se a erosividade anual das chuvas. Fazendo a média da erosividade anual das chuvas no período dos 48 anos estudados (1956 a 2003), obteve-se o valor do Fator "R" da USLE para aplicação em São Borja e na região do entorno com características climáticas semelhantes.
O período de retorno e a probabilidade de ocorrência da erosividade anual foram determinados, conforme Schwab et al. (1981), por meio das seguintes expressões:

$$
\begin{aligned}
& T=(N+1) / m \\
& P r=100 / T
\end{aligned}
$$

sendo $T$ o período de retorno, em anos, no qual o índice de erosividade é igualado ou superado; Né o número de anos de registro de dados; $m$ é o número de ordem do índice de erosividade da série considerada, quando a erosividade é colocada em ordem decrescente de magnitude, e Pr é a probabilidade de ocorrência do índice de erosividade, em percentagem.

Utilizando os registros pluviográficos obtidos na série de dados entre 1956 e 2003, em São Borja, RS, foi estabelecida a relação linear e potencial entre a erosividade das chuvas calculada pelo índice $E I_{30}$ e o coeficiente de chuvas, conforme proposto por Lombardi Neto (1977), pelas seguintes expressões:

$$
\begin{aligned}
& E I_{30}=a+b R c \\
& E I_{30}=a R c^{b}
\end{aligned}
$$

em que $E I_{30}$ é o índice de erosividade das chuvas, MJ mm ha ${ }^{-1} \mathrm{~h}^{-1}$, a e $b$ são coeficientes de ajuste e $R c$ é o coeficiente de chuva, em $\mathrm{mm}$, dado pela seguinte relação: $\mathrm{Rc}=\mathrm{Pm}^{2} / \mathrm{Pa}$, em que $\mathrm{Pm}$ é a precipitação pluvial média mensal, em mm, e $P a$ é a precipitação pluvial média anual, em $\mathrm{mm}$.

Para cada chuva individual e erosiva, foram separados os segmentos de mesma inclinação e determinada a intensidade da chuva em cada segmento. Com isso, obteve-se uma distribuição de intensidades ao longo do tempo de duração da chuva. O programa computacional CHUVEROS verificava em que tempo ocorria o pico de maior intensidade da chuva, para fins de classificação dos padrões hidrológicos da chuva, segundo a classificação proposta por Horner \& Jens (1942). Com base no padrão hidrológico de cada chuva foi calculada a percentagem do total das chuvas que representa cada padrão hidrológico, em número, em volume e em erosividade.

\section{RESULTADOS E DISCUSSÃO}

No período de 1956 a 2003, a precipitação pluvial média anual, em São Borja, RS, foi de 1.540 mm (Quadro 1). Desse total, a quantidade média anual das chuvas erosivas foi de $1.393 \mathrm{~mm}$ ano-1 e das chuvas não-erosivas foi de $147 \mathrm{~mm}^{-1} \mathrm{ano}^{-1}$. $\mathrm{O}$ ano de 2002 foi o de maior pluviosidade, com o total de chuvas de $2.816 \mathrm{~mm}$, enquanto o ano de menor pluviosidade foi $1956 \mathrm{com} 790 \mathrm{~mm}$ de chuva. Em relação às médias mensais, os meses de março, abril e outubro 
Quadro 1. Valores mensais, anuais e médios mensais da precipitação pluvial (mm) em São Borja, RS, período de 1956 a 2003, com as respectivas medidas estatísticas de dispersão

\begin{tabular}{|c|c|c|c|c|c|c|c|c|c|c|c|c|c|}
\hline Ano & Jan. & Fev. & Mar. & Abr. & Maio & Jun. & Jul. & Ago. & Set. & Out. & Nov. & Dez. & Total \\
\hline 1956 & 1,5 & 36,2 & 83,9 & 101,6 & 111,4 & 17,1 & 110,0 & 20,4 & 88,5 & 83,0 & 35,0 & 101,5 & 790,1 \\
\hline 1957 & 180,5 & 33,0 & 39,0 & 91,1 & 43,7 & 82,2 & 60,5 & 69,5 & 164,0 & 280,3 & 57,0 & 151,0 & $1.251,8$ \\
\hline 1958 & 22,2 & 93,0 & 187,6 & 143,2 & 87,2 & 92,0 & 100,6 & 68,1 & 128,2 & 50,1 & 294,6 & 249,0 & $1.515,8$ \\
\hline 1959 & 139,8 & 289,8 & 188,4 & 304,4 & 136,1 & 171,2 & 27,9 & 121,8 & 67,6 & 185,8 & 79,3 & 144,7 & $1.856,8$ \\
\hline 1960 & 87,0 & 115,6 & 91,9 & 120,5 & 30,4 & 106,3 & 91,1 & 110,9 & 101,3 & 152,5 & 44,5 & 21,2 & $1.073,2$ \\
\hline 1961 & 50,2 & 89,1 & 108,7 & 192,9 & 215,2 & 234,7 & 100,8 & 48,0 & 156,3 & 256,3 & 247,8 & 42,2 & $1.742,2$ \\
\hline 1962 & 55,7 & 46,2 & 351,7 & 113,2 & 84,0 & 10,0 & 20,1 & 114,7 & 64,9 & 26,8 & 145,8 & 36,6 & $1.069,7$ \\
\hline 1963 & 97,2 & 45,5 & 96,9 & 39,8 & 107,7 & 71,0 & 31,7 & 41,4 & 200,7 & 129,6 & 160,0 & 150,8 & $1.172,3$ \\
\hline 1964 & 44,7 & 122,6 & 203,8 & 247,9 & 3,0 & 35,0 & 26,3 & 168,3 & 114,3 & 57,5 & 102,9 & 62,7 & $1.189,0$ \\
\hline 1965 & 11,3 & 124,7 & 59,0 & 215,9 & 142,4 & 56,5 & 90,5 & 87,6 & 194,5 & 212,4 & 53,6 & 141,1 & $1.389,5$ \\
\hline 1966 & 86,0 & 103,0 & 166,7 & 182,4 & 21,8 & 106,0 & 157,4 & 23,8 & 72,3 & 144,5 & 134,9 & 141,0 & $1.339,8$ \\
\hline 1967 & 70,1 & 128,9 & 136,2 & 26,1 & 142,8 & 36,5 & 115,9 & 131,6 & 102,2 & $163,4^{*}$ & $138,2^{*}$ & 68,8 & $1.260,7$ \\
\hline 1968 & 47,8 & 135,7 & 122,8 & 38,0 & 10,7 & 59,1 & 31,0 & 35,5 & 73,6 & 227,7 & 98,7 & 90,6 & 971,2 \\
\hline 1969 & 105,6 & 104,0 & 39,3 & 49,4 & 43,3 & 62,0 & 61,4 & 37,1 & 116,5 & 115,3 & 101,5 & 104,4 & 939,8 \\
\hline 1970 & 160,0 & 79,3 & 168,7 & 11,7 & 50,0 & $110,9^{*}$ & 66,7 & 132,9 & 143,1 & $163,4^{*}$ & $138,2^{*}$ & $130,1^{*}$ & $1.355,0$ \\
\hline 1971 & 125,0 * & $124,1^{*}$ & $155,9^{*}$ & $177,9^{*}$ & $112,7^{*}$ & $110,9 *$ & $89,4^{*}$ & $84,4^{*}$ & $128,5^{*}$ & $163,4^{*}$ & $138,2^{*}$ & $130,1^{*}$ & $1.540,5$ \\
\hline 1972 & $125,0^{*}$ & $124,1^{*}$ & $155,9^{*}$ & $177,9^{*}$ & $112,7^{*}$ & 585,8 & 145,3 & 175,4 & 154,9 & 195,1 & 205,9 & 79,6 & $2.237,6$ \\
\hline 1973 & 222,8 & 216,6 & 102,2 & 258,5 & 115,8 & 121,7 & 92,7 & 146,2 & 155,8 & 78,2 & 23,9 & 151,4 & $1.685,8$ \\
\hline 1974 & 249,8 & 94,9 & 67,0 & 23,8 & 154,9 & 90,8 & 43,9 & 85,3 & 48,5 & 10,0 & 113,6 & 10,6 & 993,1 \\
\hline 1975 & 191,9 & 64,0 & 308,1 & 169,7 & 138,9 & 128,4 & 90,0 & 153,9 & 114,7 & 162,6 & 88,9 & 140,5 & $1.751,6$ \\
\hline 1976 & 245,0 & 135,5 & 279,6 & 122,7 & 74,8 & 52,3 & 131,7 & 90,0 & 143,1 & 174,3 & 161,2 & 177,6 & $1.787,8$ \\
\hline 1977 & 250,9 & 130,8 & 111,6 & 125,0 & 150,4 & 42,7 & 119,8 & 61,0 & 167,5 & 34,8 & 147,3 & 135,7 & $1.477,5$ \\
\hline 1978 & 56,9 & 51,2 & 57,3 & 29,0 & 77,0 & 83,9 & 128,1 & 31,7 & 53,4 & 138,4 & 257,8 & 33,8 & 998,5 \\
\hline 1979 & 35,7 & 148,8 & 61,9 & 136,9 & 68,7 & 27,5 & 124,7 & 118,4 & 193,3 & 291,8 & 120,6 & 167,9 & $1.496,2$ \\
\hline 1980 & 28,5 & 105,7 & 217,5 & 67,7 & 161,6 & 171,0 & 55,9 & 123,2 & 59,3 & 295,5 & 220,2 & 111,0 & $1.617,1$ \\
\hline 1981 & 127,6 & 132,8 & 12,5 & 96,6 & 43,6 & 84,1 & 28,3 & 13,8 & 96,6 & 60,8 & 115,8 & 198,4 & $1.010,9$ \\
\hline 1982 & 6,1 & 137,0 & 96,0 & 55,5 & 150,3 & 171,8 & 116,9 & 277,5 & 160,5 & 103,8 & 352,1 & 102,3 & $1.729,8$ \\
\hline 1983 & 148,6 & 179,8 & 178,5 & 364,2 & 257,5 & 47,1 & 123,8 & 28,1 & 28,1 & 117,3 & 79,2 & 29,1 & $1.581,3$ \\
\hline 1984 & 216,2 & 85,4 & 84,3 & 244,8 & 295,1 & 163,9 & 90,8 & 53,4 & 214,3 & 188,0 & 103,5 & 68,6 & $1.808,3$ \\
\hline 1985 & 6,2 & 226,2 & 247,8 & 274,2 & 249,9 & 167,2 & 217,2 & 94,5 & 248,7 & 91,9 & 10,2 & 82,7 & $1.916,7$ \\
\hline 1986 & 87,2 & 169,4 & 464,5 & 441,1 & 247,9 & 245,4 & 89,8 & 163,2 & 156,9 & 166,3 & 325,0 & 26,2 & $2.582,9$ \\
\hline 1987 & 215,4 & 5,9 & 246,8 & 322,9 & 110,5 & 121,4 & 294,6 & 80,5 & 132,2 & 63,9 & 61,6 & 79,6 & $1.815,3$ \\
\hline 1988 & 170,4 & 112,1 & 120,2 & 171,4 & 15,6 & 65,0 & 39,9 & 43,7 & 198,1 & 71,9 & 85,3 & 103,4 & $1.197,0$ \\
\hline 1989 & 287,7 & 1,9 & 118,3 & 191,3 & 6,3 & 133,4 & 62,2 & 128,3 & 155,2 & 158,1 & 104,6 & 154,6 & $1.531,9$ \\
\hline 1990 & 74,6 & 89,4 & 271,5 & 405,9 & 42,2 & 124,4 & 64,7 & 24,2 & 189,2 & 225,6 & 201,4 & 140,4 & $1.835,5$ \\
\hline 1991 & 82,0 & 97,6 & 66,8 & 163,3 & 68,8 & 140,9 & 66,2 & 14,0 & 100,1 & 67,3 & 107,1 & 245,0 & $1.219,1$ \\
\hline 1992 & 61,4 & 161,7 & 155,3 & 275,0 & 177,3 & 42,7 & 50,1 & 46,0 & 82,5 & 165,3 & 68,9 & 115,6 & $1.401,8$ \\
\hline 1993 & 289,0 & 3,9 & 174,8 & 135,9 & 217,2 & 87,5 & 102,5 & 12,2 & 43,9 & 171,5 & 360,8 & 199,1 & $1.818,3$ \\
\hline 1994 & 74,4 & 256,4 & 107,4 & 159,6 & 140,1 & 88,7 & 144,6 & 51,1 & 95,2 & 136,2 & 177,6 & 86,9 & $1.518,2$ \\
\hline 1995 & 120,7 & 125,0 & 136,1 & 32,4 & 139,2 & 29,6 & 52,8 & 105,0 & 82,7 & 84,2 & 15,1 & 135,1 & $1.057,9$ \\
\hline 1996 & 285,3 & 164,6 & 1,5 & 257,9 & 6,6 & 85,4 & 27,3 & 60,3 & 89,9 & 210,4 & 93,8 & 173,7 & $1.486,7$ \\
\hline 1997 & 133,8 & 209,8 & 44,3 & 17,2 & 115,7 & 53,2 & 33,6 & 35,6 & 66,4 & 492,6 & 257,0 & 256,9 & $1.916,1$ \\
\hline 1998 & 247,9 & 277,2 & 183,8 & 464,4 & 48,6 & 69,2 & 114,6 & 99,2 & 151,7 & 118,4 & 56,3 & 174,2 & $2.005,5$ \\
\hline 1999 & 8,4 & 233,5 & 92,4 & 266,2 & 270,5 & 97,0 & 93,1 & 15,5 & 180,8 & 180,1 & 83,9 & 147,3 & $1.668,7$ \\
\hline 2000 & 102,4 & 69,7 & 286,3 & 117,4 & 173,0 & 216,9 & 53,7 & 91,8 & 155,2 & 266,9 & 163,3 & 259,7 & $1.956,3$ \\
\hline 2001 & 342,7 & 73,4 & 208,7 & 271,0 & 36,0 & 174,3 & 65,9 & 79,4 & 167,4 & 158,1 & 82,2 & 11,8 & $1.670,9$ \\
\hline 2002 & 114,8 & 30,0 & 328,3 & 293,5 & 190,5 & 128,2 & 179,7 & 194,2 & 199,1 & 584,9 & 236,7 & 336,5 & $2.816,4$ \\
\hline 2003 & 106,8 & 243,2 & 266,2 & 251,0 & 9,4 & 119,7 & 64,6 & 60,6 & 64,2 & 168,7 & 184,5 & 343,4 & $1.882,3$ \\
\hline Média & 125,0 & 124,1 & 155,9 & 177,9 & 112,7 & 110,9 & 89,4 & 84,4 & 128,5 & 163,4 & 138,2 & 130,1 & $1.540,5$ \\
\hline DP & 88,8 & 68,0 & 96,5 & 113,4 & 77,8 & 90,3 & 53,4 & 56,1 & 54,3 & 106,2 & 86,7 & 78,0 & 464,6 \\
\hline CV (\%) & 71,0 & 54,8 & 61,9 & 63,7 & 69,1 & 83,2 & 59,7 & 66,4 & 42,2 & 65,0 & 62,7 & 59,9 & 30,2 \\
\hline Máx & 342,7 & 289,8 & 464,5 & 464,4 & 295,1 & 585,8 & 294,6 & 277,5 & 248,7 & 584,9 & 360,8 & 343,4 & $2.816,4$ \\
\hline Min & 1,5 & 23,9 & 12,5 & 11,7 & 3,0 & 0,0 & 20,1 & 12,2 & 28,1 & 10,0 & 10,2 & 10,6 & 790,1 \\
\hline
\end{tabular}

DP: desvio-padrão. CV: coeficiente de variação. Máx: valor máximo da série. Mín: valor mínimo da série. *Significa que o valor não foi observado dada a inexistência do dado de chuva, tendo-se utilizado o valor médio do referido mês da série levantada. 
apresentaram a maior pluviosidade média, respectivamente com 156, 178 e $163 \mathrm{~mm}$ de chuva. Por outro lado, observa-se também que os meses de julho e agosto foram os de menor pluviosidade média mensal, respectivamente, com 89 e $84 \mathrm{~mm}$ de chuva. A variação da pluviosidade média mensal entre 84 e 178 mm de chuva caracteriza o município de São Borja, RS, como de uma distribuição relativamente homogênea das chuvas ao longo do ano, mas com índices de precipitação pluvial mais baixos nos meses de inverno. No quadro 1, constata-se a ocorrência de chuvas em todos os 576 meses da série considerada, indo desde valores extremamente baixos como 1,5 mm, em janeiro de 1956, até valores extremamente altos como 586 e $585 \mathrm{~mm}$, ocorridos, respectivamente, em junho de 1972 e em outubro de 2002.

A erosividade média mensal das chuvas de São Borja, RS, variou de $268 \mathrm{MJ} \mathrm{mm} \mathrm{ha}^{-1} \mathrm{~h}^{-1}$, no mês de julho, a 1.269 MJ mm ha-1 $\mathrm{h}^{-1}$, no mês de abril (Figura 1). A tendência geral é que os maiores valores do índice $\mathrm{EI}_{30}$ concentrem-se nos meses de março e abril e os menores valores nos meses de julho e agosto. Considerando que, na região de São Borja, a principal cultura de verão é a soja e que, nos meses de março e abril é o período de colheita dessa cultura, esse período é de alto risco a perdas de solo por erosão, uma vez que os solos encontram-se menos protegidos, em face de que os resíduos deixados pela soja são de baixa quantidade e de rápida decomposição. De meados do outono até o início da primavera (entre os meses de maio a setembro), a erosividade das chuvas corresponde a apenas $24 \%$ do total (Figura 1). Dessa forma, é menor o risco de perdas de solo por erosão no período de inverno, além do que, nesse período o solo normalmente é usado com culturas de cobertura. Os altos valores de erosividade nos meses de março e abril refletem os valores excepcionais de chuva em março de 1986, que atingiu 464,5 mm, e em abril de 1983 , que atingiu 364,2 mm (Quadro 1), propiciando valores de erosividade de 6.078,3 MJ mm ha-1 $\mathrm{h}^{-1}$ e de 4.837,6 $\mathrm{MJ} \mathrm{mm} \mathrm{ha}^{-1} \mathrm{~h}^{-1}$, respectivamente (Quadro 2). Entre outubro e dezembro, verifica-se considerável variação na erosividade média mensal das chuvas de 886 a $1.073 \mathrm{MJ} \mathrm{mm} \mathrm{ha}^{-1} \mathrm{~h}^{-1}$ (Figura 1). Esse é o período em que ocorre o preparo do solo e a semeadura das principais culturas anuais de verão na região de São Borja, RS. Portanto, nesse período, com o solo mais exposto e com alta erosividade das chuvas, os cuidados no controle da erosão também deverão ser intensos.

No período estudado, o mês em que ocorreu a maior erosividade das chuvas foi junho de 1972, com valor de 7.857 MJ mm ha-1 $\mathrm{h}^{-1}$ (Quadro 2). Esse, sem dúvidas, foi um valor excepcional, resultado de um total de 586 mm de precipitação pluvial (Quadro 1). Esses picos excepcionais são responsáveis por provocar grandes danos nas lavouras cultivadas pela ocorrência do processo de erosão hídrica. Em alguns meses do período estudado, a erosividade das chuvas foi zero (Quadro 2), mesmo que em nenhum mês da série

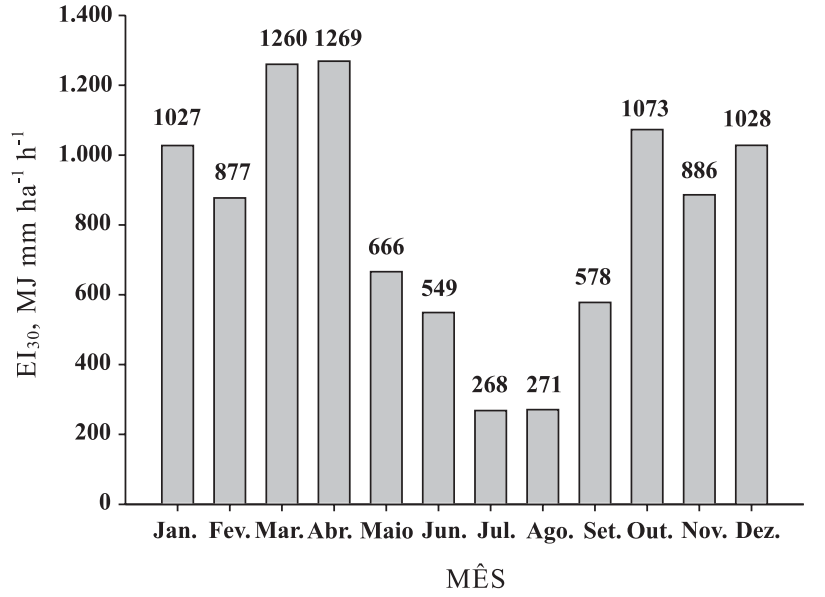

Figura 1. Erosividade média mensal das chuvas de São Borja, RS, no período de 1956 a 2003, determinada pelo índice $\mathrm{EI}_{30}$.

estudada tenha havido zero de chuva (Quadro 1). Isso significa que, nos meses de erosividade zero (Quadro 2), as chuvas que ocorreram (Quadro 1) não foram erosivas.

A erosividade média anual das chuvas em São Borja, RS, com base no período de estudo é de 9.751 MJ mm ha-1 $\mathrm{h}^{-1}$ (Figura 2). A erosividade média anual de $9.751 \mathrm{MJ} \mathrm{mm} \mathrm{ha}^{-1} \mathrm{~h}^{-1}$ representa o valor do Fator "R" da USLE para uso local. Esse valor do fator "R" da USLE pode ser utilizado com segurança para localidades próximas, no entorno de São Borja, que é o caso de nove municípios que compõem a região agroecológica 9 (Rio Grande do Sul, 1994), com características climáticas semelhantes. Dessa forma, amplia-se a possibilidade da utilização da Equação Universal de Perdas de Solo no planejamento conservacionista da atividade agrícola.

A erosividade anual das chuvas no período do estudo foi bastante variável (Figura 2). O valor médio anual de $9.571 \mathrm{MJ} \mathrm{mm} \mathrm{ha}^{-1} \mathrm{~h}^{-1}$ para a erosividade das chuvas apresentou um desvio-padrão de $4.587 \mathrm{MJ} \mathrm{mm} \mathrm{ha}^{-1} \mathrm{~h}^{-1}$ e um coeficiente de variação de $47 \%$ (Quadro 2). Os valores médias anuais extremos foram de 3.166 e de $23.088 \mathrm{MJ} \mathrm{mm} \mathrm{ha-1} \mathrm{h}^{-1}$, em 1960 e em 2002, respectivamente. Conforme Wischmeier (1976) a Equação Universal de Perdas de Solo (USLE) é uma ferramenta de predição das perdas de solo por erosão hídrica que apresenta algumas limitações, sendo a principal delas a de não ser um eficiente instrumento para predizer as perdas em um curto período, como, por exemplo, de um ano. A principal razão para tal é que a USLE utiliza como Fator "R" o valor da erosividade média anual das chuvas, cuja variabilidade anual é considerável, conforme se pode observar no quadro 2, para o caso de São Borja, RS. Por essa razão, a USLE é apenas recomendada para predizer perdas médias de solo sobre longos períodos de tempo, no mínimo, de 10 anos. 
Quadro 2. Valores mensais, anuais e médios do índice de erosividade $\mathrm{EI}_{30}$ em São Borja, RS, período de 1956 a 2003, com as respectivas medidas estatísticas de dispersão

\begin{tabular}{|c|c|c|c|c|c|c|c|c|c|c|c|c|c|}
\hline Ano & Jan. & Fev. & Mar. & Abr. & Maio & Jun. & Jul. & Ago. & Set. & Out. & Nov. & Dez. & Total \\
\hline & \multicolumn{13}{|c|}{ 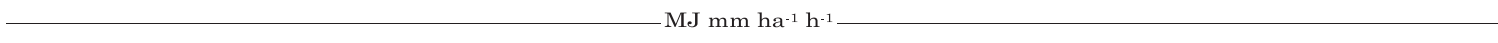 } \\
\hline 1956 & 0,0 & 34,9 & 199,1 & 720,5 & 681,1 & 0,0 & 316,8 & 0,0 & 292,4 & 182,9 & 220,3 & 584,5 & $3.232,5$ \\
\hline 1957 & $1.345,3$ & 108,1 & 151,6 & 251,9 & 53,8 & 92,8 & 224,5 & 191,4 & 228,5 & $1.389,9$ & 246,0 & 806,8 & $5.090,6$ \\
\hline 1958 & 41,6 & 282,5 & $2.292,9$ & $1.815,5$ & 586,2 & 316,3 & 254,6 & 72,3 & 571,3 & 106,4 & $2.753,2$ & $1.293,3$ & $10.386,1$ \\
\hline 1959 & $1.092,2$ & $2.497,9$ & $1.922,0$ & $3.648,9$ & 615,7 & 701,1 & 70,0 & 198,4 & 61,7 & $1.043,0$ & 359,6 & 990,2 & $13.200,7$ \\
\hline 1960 & 575,5 & 390,6 & 248,7 & 474,4 & 51,9 & 346,3 & 212,0 & 193,5 & 128,4 & 386,1 & 158,4 & 0,0 & $3.165,8$ \\
\hline 1961 & 185,9 & 478,1 & 230,3 & $1.014,7$ & $1.543,4$ & $1.270,9$ & 131,2 & 153,8 & 767,6 & $2.201,4$ & $2.075,6$ & 124,1 & $10.177,0$ \\
\hline 1962 & 79,8 & 166,5 & $3.535,2$ & 437,3 & 113,9 & 0,0 & 0,0 & 257,5 & 78,7 & 4,6 & $1.729,5$ & 116,4 & $6.519,4$ \\
\hline 1963 & 584,0 & 107,2 & 286,1 & 39,6 & 440,7 & 116,6 & 65,1 & 61,8 & 815,7 & 800,9 & 769,5 & 710,7 & $4.797,9$ \\
\hline 1964 & 174,5 & $1.534,1$ & $1.340,0$ & $1.059,6$ & 0,0 & 19,1 & 62,4 & 427,5 & 859,9 & 335,5 & 291,8 & 131,3 & $6.235,7$ \\
\hline 1965 & 0,0 & 968,0 & 329,4 & $1.168,0$ & 821,5 & 164,7 & 373,9 & 171,1 & $1.017,2$ & $1.108,6$ & 38,9 & $1.093,0$ & $7.254,3$ \\
\hline 1966 & 109,8 & 289,4 & $1.504,4$ & 997,4 & 0,0 & 501,9 & 451,7 & 11,3 & 154,1 & 563,2 & 503,7 & $1.436,9$ & $6.523,8$ \\
\hline 1967 & 501,3 & $1.350,4$ & 691,0 & 239,7 & 504,2 & 84,5 & 317,6 & 426,4 & 551,6 & $1072,8^{*}$ & $885,7^{*}$ & 604,4 & $7.229,6$ \\
\hline 1968 & 122,0 & $1.028,2$ & 472,3 & 49,6 & 0,0 & 207,2 & 11,1 & 45,4 & 198,2 & 948,9 & 470,8 & 838,4 & $4.392,1$ \\
\hline 1969 & 302,7 & 170,6 & 36,3 & 139,0 & 56,2 & 61,9 & 66,0 & 21,3 & 486,2 & 515,9 & 491,4 & $1.065,3$ & $3.412,8$ \\
\hline 1970 & $1.531,2$ & 147,3 & 902,5 & 0,0 & 31,4 & $548,8^{*}$ & 162,6 & 403,4 & 593,5 & $1.072,8^{*}$ & $885,7^{*}$ & $1.028,2^{*}$ & $7.307,4$ \\
\hline 1971 & $1.027,3^{*}$ & $877,2^{*}$ & $1.259,9^{*}$ & $1.268,9^{*}$ & $665,6^{*}$ & $548,8^{*}$ & $267,6^{*}$ & $270,9 *$ & $578,0^{*}$ & $1.072,8^{*}$ & $885,7^{*}$ & $1.028,2^{*}$ & $9.750,9$ \\
\hline 1972 & $1.027,3^{*}$ & $877,2^{*}$ & $1.259,9^{*}$ & $1.268,9^{*}$ & $665,6^{*}$ & $7.857,1$ & 747,1 & 421,0 & $1.069,5$ & 672,2 & $1.121,6$ & 420,7 & $17.408,1$ \\
\hline 1973 & $1.593,7$ & $1.675,6$ & 243,1 & $1.490,4$ & 659,6 & 474,9 & 151,5 & 250,9 & 377,3 & 486,0 & 15,0 & $1.032,5$ & $8.450,5$ \\
\hline 1974 & $3.319,2$ & 191,1 & 727,1 & 10,8 & 908,8 & 249,3 & 58,5 & 254,9 & 103,7 & 3,5 & 381,3 & 448,8 & $6.657,0$ \\
\hline 1975 & $1.867,5$ & 227,6 & $1.829,5$ & 665,0 & 793,3 & 511,5 & 317,0 & 174,5 & 565,7 & $1.177,8$ & 590,9 & $1.131,6$ & $9.851,9$ \\
\hline 1976 & $1.253,0$ & $1.343,9$ & $2.893,5$ & 607,0 & 137,8 & 134,6 & 952,2 & 261,4 & $1.545,2$ & $1.771,1$ & 952,5 & $1.444,6$ & $13.296,8$ \\
\hline 1977 & $2.150,5$ & 856,1 & 457,4 & 979,7 & 640,1 & 42,3 & 174,4 & 42,0 & $1.295,2$ & 0,0 & 755,6 & $1.295,4$ & $8.688,7$ \\
\hline 1978 & 192,8 & 315,2 & 187,8 & 34,1 & 204,1 & 91,2 & 282,3 & 14,9 & 76,4 & 738,1 & $1.965,4$ & 73,7 & $4.176,0$ \\
\hline 1979 & 214,1 & 813,8 & 199,0 & 720,2 & 325,2 & 62,5 & 298,8 & 346,7 & 900,2 & $3.338,0$ & 830,7 & $1.058,2$ & $9.107,4$ \\
\hline 1980 & 48,5 & 487,1 & $1.554,3$ & 53,8 & 986,3 & 651,4 & 128,6 & 260,8 & 77,5 & $2.321,0$ & $1.239,3$ & 613,4 & $8.422,0$ \\
\hline 1981 & 788,7 & 444,4 & 28,9 & 326,7 & 69,4 & 117,8 & 27,4 & 0,0 & 149,5 & 189,4 & 470,6 & $2.732,1$ & $5.344,9$ \\
\hline 1982 & 0,0 & 451,3 & 754,2 & 138,3 & $1.196,0$ & 777,0 & 448,6 & $1.410,1$ & 579,5 & 477,9 & $3.486,7$ & 406,5 & $10.126,1$ \\
\hline 1983 & $2.365,4$ & $1.671,1$ & $1.355,3$ & $4.837,6$ & $1.291,2$ & 149,3 & 171,9 & 29,5 & 30,9 & 917,7 & 293,0 & 66,2 & $13.179,1$ \\
\hline 1984 & $1.582,4$ & 377,5 & 581,7 & $1.393,6$ & $2.598,9$ & 576,9 & 229,4 & 88,6 & 797,3 & $1.035,9$ & 303,0 & 543,8 & $10.109,0$ \\
\hline 1985 & 0,0 & $2.068,3$ & $3.209,0$ & $2.250,7$ & $2.006,6$ & $1.182,4$ & 600,0 & 110,4 & $1.068,2$ & 351,5 & 0,0 & 995,8 & $13.842,9$ \\
\hline 1986 & 241,5 & 951,4 & $6.078,3$ & $3.043,1$ & $2.312,0$ & 765,2 & 885,6 & $1.839,7$ & 510,7 & 908,9 & $2.079,5$ & 86,1 & $19.702,0$ \\
\hline 1987 & $2.347,9$ & 359,0 & $1.924,9$ & $2.509,2$ & 425,2 & 247,0 & $1.395,1$ & 341,7 & $1.086,2$ & 440,4 & 171,4 & 248,9 & $11.496,9$ \\
\hline 1988 & 894,1 & 450,3 & 718,1 & 741,3 & 19,2 & 159,3 & 37,0 & 64,7 & 509,8 & 158,9 & 508,1 & 867,9 & $5.128,7$ \\
\hline 1989 & $2.949,5$ & 506,4 & 501,8 & $1.461,7$ & 0,0 & 513,7 & 50,4 & 568,6 & 791,9 & 673,5 & 423,4 & $1.429,5$ & $9.870,4$ \\
\hline 1990 & 344,7 & 479,4 & $3.333,2$ & $1.784,6$ & 43,0 & 241,5 & 186,0 & 13,0 & $1.155,0$ & $2.077,9$ & 668,6 & $1.332,0$ & $11.658,9$ \\
\hline 1991 & 556,5 & 398,2 & 259,4 & $1.969,2$ & 67,1 & $1.063,1$ & 172,1 & 0,0 & 403,3 & 110,3 & 356,8 & $2.070,8$ & $7.426,8$ \\
\hline 1992 & 424,8 & $1.867,7$ & $1.265,6$ & $2.651,4$ & 933,5 & 38,9 & 51,5 & 154,9 & 309,6 & 705,7 & 239,8 & 550,2 & $9.193,6$ \\
\hline 1993 & $3.494,3$ & 105,3 & 709,2 & $1.428,4$ & $2.001,6$ & 443,9 & 162,2 & 0,0 & 65,0 & $1.882,1$ & $1.752,1$ & $1.550,7$ & $13.594,8$ \\
\hline 1994 & 336,4 & $2.505,8$ & 694,0 & $1.086,6$ & 405,7 & 293,6 & 546,9 & 28,6 & 189,4 & 736,4 & $1.079,6$ & $1.105,5$ & $9.008,5$ \\
\hline 1995 & 672,5 & 486,2 & 999,8 & 162,3 & $1.480,1$ & 75,2 & 34,8 & 267,6 & 188,0 & 423,8 & 17,4 & $1.880,5$ & $6.688,2$ \\
\hline 1996 & $2.168,8$ & 519,6 & 107,0 & $2.711,6$ & 0,0 & 244,7 & 70,3 & 112,1 & 196,7 & 608,4 & 342,5 & $1.565,1$ & $8.646,8$ \\
\hline 1997 & $1.846,7$ & $1.972,9$ & 162,6 & 860,8 & 475,5 & 141,8 & 35,5 & 95,1 & $1.321,6$ & $3.656,5$ & $3.086,2$ & $2.982,0$ & $16.637,2$ \\
\hline 1998 & $2.589,8$ & $3.367,4$ & $1.578,5$ & $3.041,4$ & 80,6 & 214,9 & 337,3 & 166,7 & 975,1 & $1.194,1$ & 215,5 & 697,5 & $14.458,8$ \\
\hline 1999 & 0,0 & $2.937,4$ & 800,9 & $1.262,6$ & $1.280,4$ & 226,9 & 144,2 & 31,4 & 550,8 & 844,1 & 260,7 & $1.095,4$ & $9.434,8$ \\
\hline 2000 & 592,8 & 178,1 & $2.419,9$ & 569,3 & $1.772,3$ & 971,7 & 88,1 & $1.006,4$ & $1.310,0$ & $2.891,7$ & $1.486,0$ & $1.905,3$ & $15.191,6$ \\
\hline 2001 & $3.462,4$ & 375,5 & $2.292,5$ & $3.354,9$ & 202,6 & $1.237,2$ & 221,9 & 191,5 & 836,7 & $1.722,6$ & 233,6 & 0,0 & $14.131,4$ \\
\hline 2002 & $1.209,5$ & 117,2 & $2.809,1$ & $2.311,2$ & $1.801,7$ & 537,7 & 518,6 & $1.417,8$ & $1.055,4$ & $5.346,0$ & $3.389,3$ & $2.574,3$ & $23.087,8$ \\
\hline 2003 & $1.102,3$ & $2.297,5$ & $3.136,8$ & $1.856,6$ & 0,0 & $1.068,1$ & 330,8 & 130,5 & 267,7 & 826,8 & $1.033,2$ & $3.296,7$ & $15.347,0$ \\
\hline Média & $1.027,3$ & 877,2 & $1.259,9$ & $1.268,9$ & 665,6 & 548,8 & 267,6 & 270,9 & 578,0 & $1.072,8$ & 885,7 & $1.028,2$ & $9.750,9$ \\
\hline DP & $1.013,3$ & 841,0 & $1.226,2$ & 114,8 & 694,6 & $1.124,8$ & 274,9 & 383,3 & 417,8 & $1.046,0$ & 891,0 & 784,3 & $4.586,7$ \\
\hline CV (\%) & 98,6 & 95,9 & 97,3 & 87,9 & 104,4 & 204,9 & 102,7 & 141,5 & 72,3 & 97,5 & 100,6 & 76,3 & 47,0 \\
\hline Máx & $3.494,3$ & $3.367,4$ & $6.078,3$ & $4.837,6$ & $2.598,9$ & $7.857,1$ & $1.395,1$ & $1.839,7$ & $1.545,2$ & $5.346,0$ & $3.486,7$ & $3.296,7$ & $23.087,8$ \\
\hline Min & 0,0 & 34,9 & 28,9 & 0,0 & 0,0 & 0,0 & 0,0 & 0,0 & 30,9 & 0,0 & 0,0 & 0,0 & $3.165,8$ \\
\hline
\end{tabular}

DP: desvio-padrão. CV: coeficiente de variação. Máx: valor máximo da série. Mín: valor mínimo da série. * Dados de chuva nãodisponíveis; utilizou-se o valor médio do referido mês.

A erosividade média anual das chuvas (Fator "R" da USLE) para São Borja, RS, é uma das mais altas do País. Supera os valores obtidos no Estado de São Paulo por Tommaselli et al. (1999) que obtiveram, para Presidente Prudente, SP, valor de 7.161 MJ mm ha ${ }^{-1} \mathrm{~h}^{-1}$; por Roque et al. (2001), para Piraju, SP, valor de $7.074 \mathrm{MJ} \mathrm{mm} \mathrm{ha}^{-1} \mathrm{~h}^{-1}$; por Colodro et al. (2002), para Teodoro Sampaio, SP, de $7.172 \mathrm{MJ} \mathrm{mm} \mathrm{ha}^{-1} \mathrm{~h}^{-1}$ e os obtidos no estado de Goiás por Silva et al. (1997), de $8.353 \mathrm{MJ} \mathrm{mm} \mathrm{ha}^{-1} \mathrm{~h}^{-1}$, para
Goiânia, GO, e para o estado de Mato Grosso valores obtidos por Morais et al. (1991), para Barranquinho e Flechas, MT, de, respectivamente, 8.493 e 7.830 MJ mm ha ${ }^{-1} \mathrm{~h}^{-1}$, os valores médios anuais obtidos no Estado de Santa Catarina por Bertol (1993, 1994), para Lages e Campos Novos, SC, de 5.694 e $6.329 \mathrm{MJ} \mathrm{mm} \mathrm{ha}^{-1} \mathrm{~h}^{-1}$, respectivamente, e os valores obtidos em Minas Gerais por Melo Marques et al. (1998) de 5.835 MJ mm ha-1 $\mathrm{h}^{-1}$, para Sete Lagoas, MG. O valor mais próximo ao de São Borja, RS, foi 


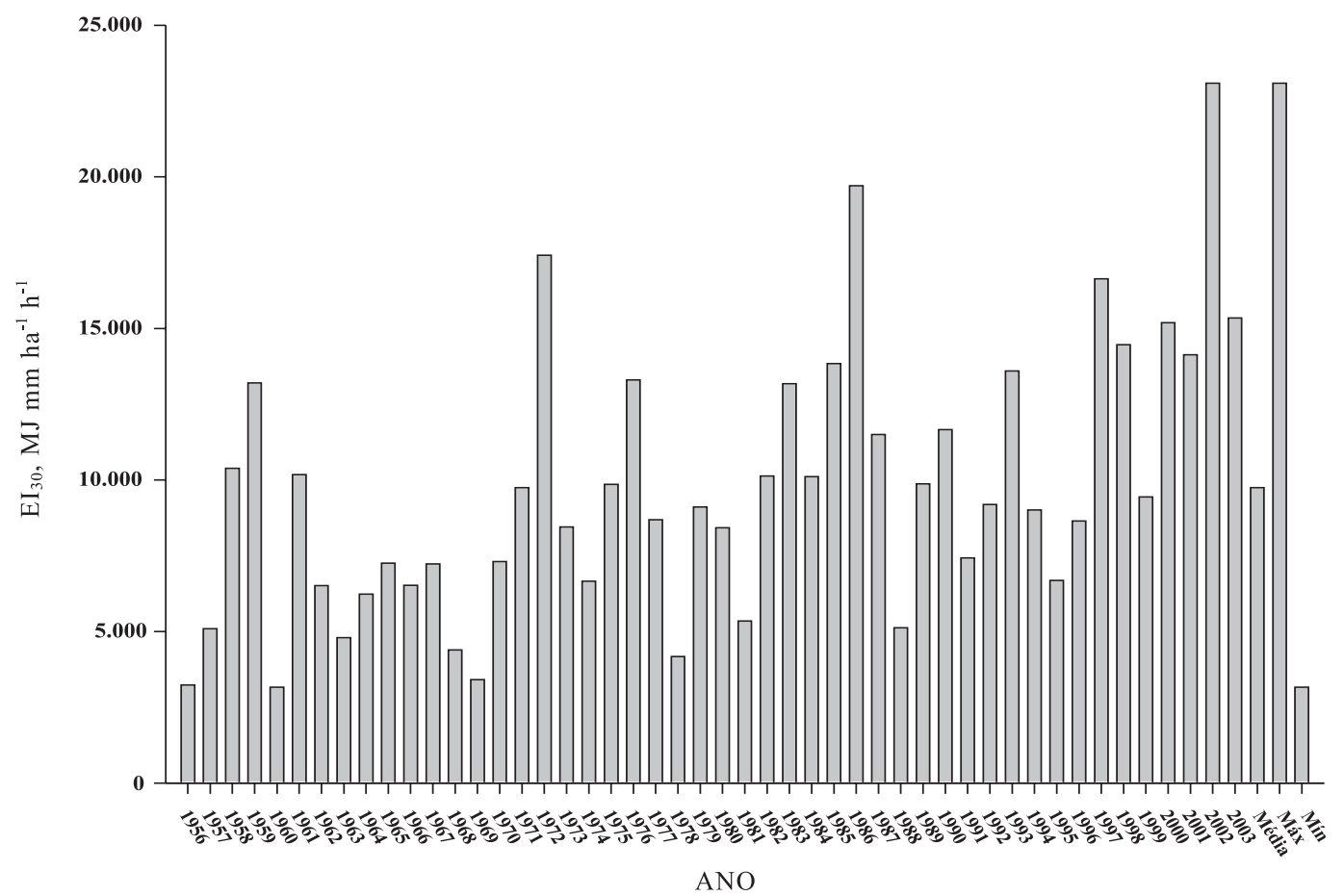

Figura 2. Erosividade anual das chuvas de São Borja, RS, determinada pelo índice $\mathrm{EI}_{30}$, no período de 1956 a 2003.

obtido por Peñalva Bazzano et al. (2007) em Quarai, $\mathrm{RS}$, de 9.292 MJ mm ha-1 $\mathrm{h}^{-1}$, que fica quase na mesma posição de longitude oeste, mas levemente mais ao sul na latitude.

Foram obtidas relação linear e potencial entre o coeficiente de chuvas (Rc) e a erosividade das chuvas (expresso pelo índice $\mathrm{EI}_{30}$ ), dadas pelas seguintes expressões:

$$
\begin{array}{cc}
E I_{30}=99,646+63,874 R c & R^{2}=0,771 \\
E I_{30}=55,564 R c^{1,1054} & R^{2}=0,841
\end{array}
$$

em que $\mathrm{EI}_{30}$ é o índice de erosividade da chuva (MJ mm ha ${ }^{-1} \mathrm{~h}^{-1}$ ) e $R c$ é o coeficiente de chuva, dado em $\mathrm{mm}\left(\mathrm{Rc}=\mathrm{Pm}^{2} / \mathrm{Pa}\right.$, em que $\mathrm{Pm}=$ é a precipitação média mensal, em mm e Pa é a precipitação total média anual, em $\mathrm{mm}$ ). Tanto a relação linear (Equação 7), quanto a relação potencial (Equação 8) entre o índice $\mathrm{EI}_{30}$ e o coeficiente de chuvas (Rc) têm bom coeficiente de determinação. Isso indica que essas relações podem ser utilizadas para determinar a erosividade média anual das chuvas, pelo índice $E I_{30}$, em locais com características climáticas semelhantes e sem dados pluviográficos disponíveis, especialmente na região agroecológica 9 (Rio Grande do Sul, 1994), que compreende nove municípios no entorno de São Borja, RS.

Observa-se no, quadro 3, que o valor do Fator "R" da USLE estimado pela relação linear (Equação 7) é idêntico ao obtido pelos dados observados calculados pelo índice $\mathrm{EI}_{30}$, enquanto essa estimativa calculada pela relação potencial (Equação 8) é levemente diferente, mas, mesmo assim, muito próxima do valor real. Isso permite concluir que o valor médio anual da erosividade das chuvas (fator "R" da Equação Universal de Perdas de Solo - USLE), pode ser estimado por qualquer uma das relações obtidas por regressão, mesmo que, pela estimativa mais exata, a relação linear (Equação 7) possa ser a mais indicada (Quadro 3). Quanto à distribuição mensal dos valores de erosividade, observa-se, no quadro 3 , pequena diferença quando se comparam os valores de $E I_{30}$ com os valores estimados pelas equações 7 e 8 , razão pela qual para estimar a distribuição mensal do índice de erosividade das chuvas, as relações baseadas em pluviometria não são indicadas. Entretanto, para locais com características climáticas semelhantes e que disponham apenas de dados pluviométricos, sugere-se que a distribuição mensal da erosividade das chuvas seja estimada pelo uso da relação potencial (Equação 8), considerando que o coeficiente de determinação dessa relação é levemente maior que a da relação linear (Equação 7).

Na figura 3, observam-se a dispersão e a linha de ajuste dos pontos de acordo com a relação potencial entre a erosividade (índice $\mathrm{EI}_{30}$ ) e o coeficiente de chuvas $(\mathrm{Rc})$. A linha de tendência ajustada, mesmo que de forma potencial, tem aspecto linear, tendo em vista o expoente ter valor muito próximo da unidade. A utilização da equação 8 dá consistência à relação obtida, visto que, se em determinado mês ocorrer zero 
Quadro 3. Relação linear e potencial da quantidade de precipitação pluvial (mm) com a erosividade das chuvas em São Borja, RS, no período 1956-2003

\begin{tabular}{|c|c|c|c|c|c|c|c|c|}
\hline \multirow{3}{*}{ Mês } & \multirow{3}{*}{$\begin{array}{c}\text { Chuva } \\
\text { média mensal }\end{array}$} & \multirow{3}{*}{$\begin{array}{c}\text { Coeficiente } \\
\text { de chuva } \\
\text { - Rc - }\end{array}$} & & & \multicolumn{4}{|c|}{$\mathrm{EI}_{30}$ calculado } \\
\hline & & & \multicolumn{2}{|c|}{ EI $I_{30}$ observado } & \multicolumn{2}{|c|}{ Equação 7} & \multicolumn{2}{|c|}{ Equação 8} \\
\hline & & & Absoluto & Relativo & Absoluto & Relativo & Absoluto & Relativo \\
\hline & $\mathrm{mm}$ & $\mathrm{mm}$ & $\begin{array}{l}\text { MJ mm } \\
\mathrm{ha}^{-1} \mathrm{~h}^{-1}\end{array}$ & $\%$ & $\begin{array}{l}\text { MJ mm } \\
\mathrm{ha}^{-1} \mathrm{~h}^{-1}\end{array}$ & $\%$ & $\begin{array}{l}\text { MJ mm } \\
\mathrm{ha}^{-1} \mathrm{~h}^{-1}\end{array}$ & $\%$ \\
\hline Jan. & 125,0 & 10,14 & $1.027,3$ & 10,5 & 747,5 & 7,7 & 719,5 & 7,4 \\
\hline Fev. & 124,1 & 10,00 & 877,2 & 9,0 & 738,2 & 7,6 & 708,0 & 7,3 \\
\hline Mar.. & 155,9 & 15,78 & $1.259,9$ & 12,9 & $1.107,4$ & 11,4 & $1.172,5$ & 12,1 \\
\hline Abr. & 177,9 & 20,54 & $1.268,9$ & 13,0 & $1.411,9$ & 14,5 & $1.569,8$ & 16,2 \\
\hline Maio & 112,7 & 8,24 & 665,6 & 6,8 & 626,3 & 6,4 & 572,2 & 5,9 \\
\hline Jun. & 110,9 & 7,98 & 548,8 & 5,6 & 609,6 & 6,3 & 552,2 & 5,7 \\
\hline Jul. & 89,4 & 5,19 & 267,6 & 2,7 & 431,0 & 4,4 & 342,9 & 3,5 \\
\hline Ago. & 84,4 & 4,62 & 270,9 & 2,8 & 395,0 & 4,1 & 301,9 & 3,1 \\
\hline Set. & 128,5 & 10,72 & 578,0 & 5,9 & 784,3 & 8,0 & 764,7 & 7,9 \\
\hline Out. & 163,4 & 17,33 & $1.072,8$ & 11,0 & $1.206,7$ & 12,4 & $1.300,8$ & 13,4 \\
\hline Nov. & 138,2 & 12,40 & 885,7 & 9,1 & 891,6 & 9,1 & 898,2 & 9,3 \\
\hline Dez. & 130,1 & 10,99 & $1.028,2$ & 10,5 & 801,5 & 8,2 & 786,0 & 8,1 \\
\hline Total & $1.540,5$ & & $9.750,9$ & 100,0 & $9.750,9$ & 100,0 & $9.688,7$ & 100,0 \\
\hline
\end{tabular}

Eq. (7): $\mathrm{EI}_{30}=99,646+63,874 \mathrm{Rc} \quad \mathrm{R}^{2}=0,7714$.

Eq. (8): $\mathrm{EI}_{30}=55,564 \mathrm{Rc}^{1,1054} \quad \mathrm{R}^{2}=0,8410$.

$\mathrm{Rc}=\mathrm{Pm}^{2} \mathrm{~Pa}^{-1}$ onde Pm: precipitação média mensal (mm) e Pa: precipitação média anual (mm).

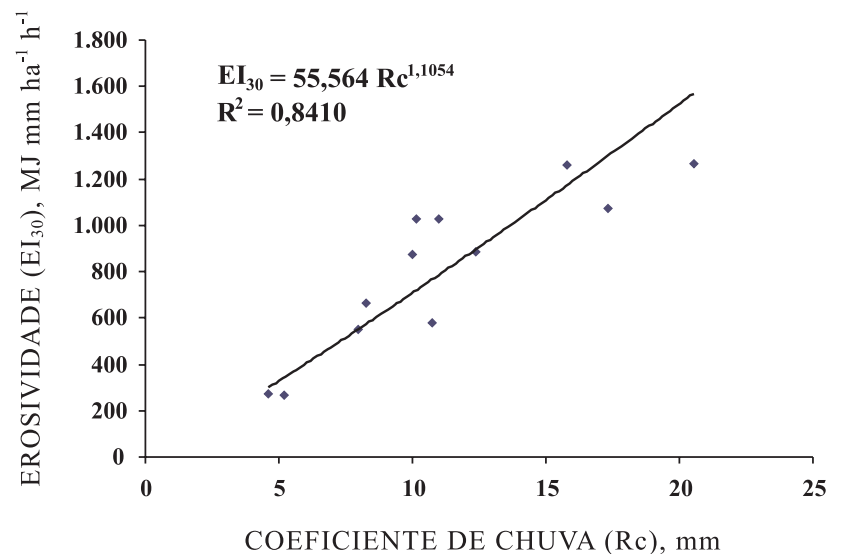

Figura 3. Curva de ajuste potencial entre o índice de erosividade $\mathrm{EI}_{30}$ médio mensal e o coeficiente de chuva $\left(\mathrm{Rc}=\mathrm{Pm}^{2} / \mathrm{Pa}\right)$ para São Borja, $\mathrm{RS}$, com base nos valores médios mensais de chuva do período entre 1956 e 2003.

de chuva, a erosividade estimada obrigatoriamente será zero, fato que não se observará com a utilização da relação linear (Equação 7). Relações potenciais altamente significativas entre o índice $\mathrm{EI}_{30}$ e o coeficiente de chuvas (Rc) também foram obtidas por Carvalho et al. (1991), em Mococa, SP, $\left(\mathrm{EI}_{30}=111,173\right.$ $\left.\mathrm{Rc}^{0,691} ; \mathrm{R}^{2}=0,991^{* *}\right)$ e por Roque et al. (2001), em Piraju, SP $\left(\mathrm{EI}_{30}=75,5488 \mathrm{Rc}^{0,8488} ; \mathrm{r}=0,9629\right)$. Já
Colodro et al. (2002), em Teodoro Sampaio, SP, obtiveram relação linear $\left(\mathrm{EI}_{30}=106,8183+46,9562\right.$ Rc; $\left.r=0,963^{* *}\right)$, enquanto Rufino et al. (1993), obtiveram relação linear para oito regiões do Estado do Paraná, com coeficiente de correlação variando de $r=0,84^{*}$ a $r=0,93^{*}$.

No quadro 4, observam-se o período de retorno e a probabilidade de ocorrência de todos os eventos de erosividade anual do período de 1956 a 2003, em São Borja, RS. O maior valor anual, de $23.088 \mathrm{MJ} \mathrm{mm}$ $\mathrm{ha}^{-1} \mathrm{~h}^{-1}$, tem um período de retorno estimado em 49 anos com probabilidade de ocorrência de $2 \%$, enquanto a menor erosividade anual do período, de $3.166 \mathrm{MJ} \mathrm{mm} \mathrm{ha}^{-1} \mathrm{~h}^{-1}$ tem um período de retorno estimado em um ano com $98 \%$ de probabilidade de ocorrência. Da mesma forma, observa-se que o valor médio da erosividade anual do período considerado, de 9.751 MJ mm ha ${ }^{-1} \mathrm{~h}^{-1}$ (que é o valor do Fator "R" da USLE em São Borja, RS), tem um período de retorno estimado de 2,2 anos com 44,9\% de probabilidade de ocorrência. Colodro et al. (2002), ao analisarem uma série de 19 anos de dados, observaram, para Teodoro Sampaio (SP), que o valor determinado para o Fator "R" da USLE tem um período de retorno de 2,33 anos, com 42,9\% de probabilidade de ocorrência.

Em relação ao número de chuvas erosivas mensais, o padrão avançado ocorreu em maior proporção do que o intermediário e o atrasado, em praticamente todos os meses do ano (Figura 4). Porém, essa proporção é 
Quadro 4. Período de retorno e probabilidade de ocorrência dos valores dos índices anuais de erosividade $\left(\mathrm{EI}_{30}\right)$, de São Borja (RS) durante o período de 1956 a 2003

\begin{tabular}{|c|c|c|c|c|}
\hline Ano & $\begin{array}{l}\text { Índice de erosividade } \\
\qquad\left(\mathrm{EI}_{30}\right)\end{array}$ & $\begin{array}{l}\text { Número de ordem } \\
\qquad(\mathrm{m})\end{array}$ & $\begin{array}{c}\text { Período de retorno } \\
(\mathrm{T})\end{array}$ & $\begin{array}{l}\text { Probabilidade de ocorrência } \\
\qquad(\operatorname{Pr})\end{array}$ \\
\hline & $\mathrm{MJ} \mathrm{mm} \mathrm{ha-1} \mathrm{h}^{-1}$ & & Ano & $\%$ \\
\hline 2002 & $23.087,8$ & 1 & 49,0 & 2,0 \\
\hline 1986 & $19.702,0$ & 2 & 24,5 & 4,1 \\
\hline 1972 & $17.408,1$ & 3 & 16,3 & 6,1 \\
\hline 1997 & $16.637,2$ & 4 & 12,3 & 8,2 \\
\hline 2003 & $15.347,0$ & 5 & 9,8 & 10,2 \\
\hline 2000 & $15.191,6$ & 6 & 8,2 & 12,2 \\
\hline 1998 & $14.458,8$ & 7 & 7,0 & 14,3 \\
\hline 2001 & $14.131,4$ & 8 & 6,1 & 16,3 \\
\hline 1985 & $13.842,9$ & 9 & 5,4 & 18,4 \\
\hline 1993 & $13.594,8$ & 10 & 4,9 & 20,4 \\
\hline 1976 & $13.296,8$ & 11 & 4,5 & 22,4 \\
\hline 1959 & $13.200,7$ & 12 & 4,1 & 24,5 \\
\hline 1983 & $13.179,1$ & 13 & 3,8 & 26,5 \\
\hline 1990 & $11.658,9$ & 14 & 3,5 & 28,6 \\
\hline 1987 & $11.496,9$ & 15 & 3,3 & 30,6 \\
\hline 1958 & $10.386,1$ & 16 & 3,1 & 32,7 \\
\hline 1961 & $10.177,0$ & 17 & 2,9 & 34,7 \\
\hline 1982 & $10.126,1$ & 18 & 2,7 & 36,7 \\
\hline 1984 & $10.109,0$ & 19 & 2,6 & 38,8 \\
\hline 1989 & $9.870,4$ & 20 & 2,5 & 40,8 \\
\hline 1975 & $9.851,9$ & 21 & 2,3 & 42,9 \\
\hline 1971 & $9.750,9$ & 22 & 2,2 & 44,9 \\
\hline 1999 & $9.434,8$ & 23 & 2,1 & 46,9 \\
\hline 1992 & $9.193,6$ & 24 & 2,0 & 49,0 \\
\hline 1979 & $9.107,4$ & 25 & 2,0 & 51,0 \\
\hline 1994 & $9.008,5$ & 26 & 1,9 & 53,1 \\
\hline 1977 & $8.688,7$ & 27 & 1,8 & 55,1 \\
\hline 1996 & $8.646,8$ & 28 & 1,8 & 57,1 \\
\hline 1973 & $8.450,5$ & 29 & 1,7 & 59,2 \\
\hline 1980 & $8.422,0$ & 30 & 1,6 & 61,2 \\
\hline 1991 & $7.426,8$ & 31 & 1,6 & 63,3 \\
\hline 1970 & $7.307,4$ & 32 & 1,5 & 65,3 \\
\hline 1965 & $7.254,3$ & 33 & 1,5 & 67,3 \\
\hline 1967 & $7.229,6$ & 34 & 1,4 & 69,4 \\
\hline 1995 & $6.688,2$ & 35 & 1,4 & 71,4 \\
\hline 1974 & $6.657,0$ & 36 & 1,4 & 73,5 \\
\hline 1966 & $6.523,8$ & 37 & 1,3 & 75,5 \\
\hline 1962 & $6.519,4$ & 38 & 1,3 & 77,6 \\
\hline 1964 & $6.235,7$ & 39 & 1,3 & 79,6 \\
\hline 1981 & $5.344,9$ & 40 & 1,2 & 81,6 \\
\hline 1988 & $5.128,7$ & 41 & 1,2 & 83,7 \\
\hline 1957 & $5.090,6$ & 42 & 1,2 & 85,7 \\
\hline 1963 & $4.797,9$ & 43 & 1,1 & 87,8 \\
\hline 1968 & $4.392,1$ & 44 & 1,1 & 89,8 \\
\hline 1978 & $4.176,0$ & 45 & 1,1 & 91,8 \\
\hline 1969 & $3.412,8$ & 46 & 1,1 & 93,9 \\
\hline 1956 & $3.232,5$ & 47 & 1,0 & 95,9 \\
\hline 1960 & $3.165,8$ & 48 & 1,0 & 98,0 \\
\hline Média & $9.750,9$ & & & \\
\hline $\mathrm{DP}$ & $4.416,3$ & & & \\
\hline CV (\%) & 45,3 & & & \\
\hline
\end{tabular}

bem menor nos meses de maio, junho, julho e agosto. Mehl et al. (2001) observaram que o padrão hidrológico atrasado provocou maiores perdas de solo que os padrões intermediários e avançados, uma vez que, quando ocorreu o pico de maior intensidade de chuva, o solo já estava mais úmido. Em relação ao volume médio mensal de chuvas, a distribuição dos padrões hidrológicos (Figura 5) foi semelhante à distribuição em relação ao número de chuvas. O padrão avançado teve maior proporção em todos os meses do ano, sendo esta proporção menos acentuada nos meses de maio, junho, julho e agosto. Também, em relação à 


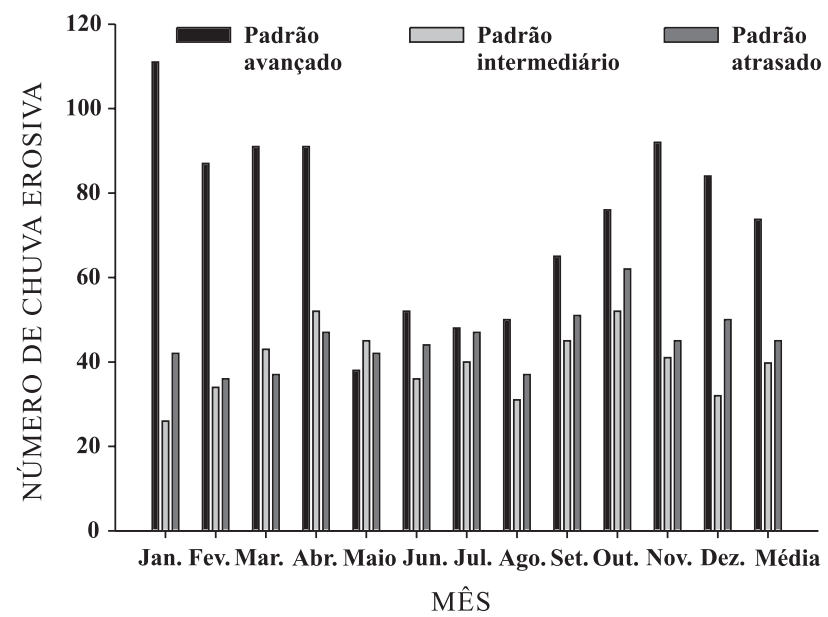

Figura 4. Distribuição do número total mensal por padrões hidrológicos das chuvas erosivas de São Borja, RS, no período de 1956 a 2003.

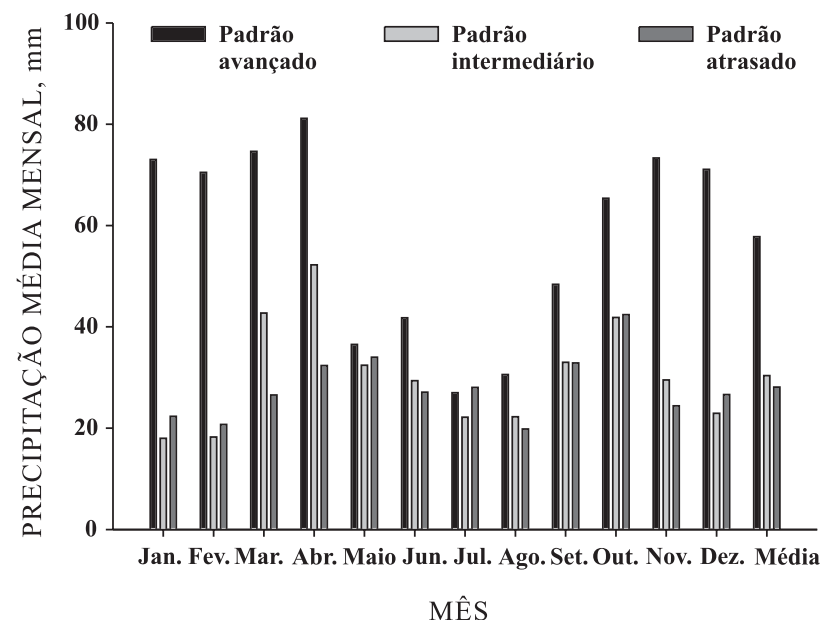

Figura 5. Distribuição da precipitação média mensal por padrões hidrológicos das chuvas erosivas de São Borja, RS, no período de 1956 a 2003.

distribuição média mensal da erosividade das chuvas (Figura 6), o padrão avançado ocorreu em maior proporção do que os padrões intermediários e atrasados, sendo essa proporção menos acentuada nos meses de maio, junho, julho, agosto e setembro.

Na média anual, a distribuição dos padrões hidrológico (avançado, intermediário e atrasado) é, respectivamente, de 47,25 e $28 \%$ para o número de chuvas erosivas, de 50, 26 e $24 \%$, para a quantidade média de chuvas, e de 53,25 e $22 \%$, para a erosividade média anual (Figura 7). Peñalva Bazzano et al. (2007) obtiveram na erosividade média anual das chuvas, respectivamente, 57,25 e $18 \%$ nos padrões avançados, intermediários e atrasados, em Quarai, RS, que é próximo do encontrado para São Borja. Com a maior proporção do padrão avançado, pode-se inferir que perdas de solo na região de São Borja, RS, são menores do que poderiam ser caso houvesse predominância dos padrões intermediários ou atrasados. Isso, conforme observado por Mehl et al. (2001), é devido ao fato de, nas chuvas de padrão hidrológico avançado, no momento do pico de maior intensidade de chuva, o solo está menos úmido do que no caso dos outros padrões, por conseguinte com desagregação, selamento superficial e transporte de solo menor do que nos outros padrões. Este fato foi comprovado por Eltz et al. (2001) que observaram maior erosão em chuvas do padrão atrasado em relação aos padrões intermediários e avançados, que não diferiram entre si, o que foi explicado pela alteração da superfície e conteúdo de água do solo no decorrer da chuva.

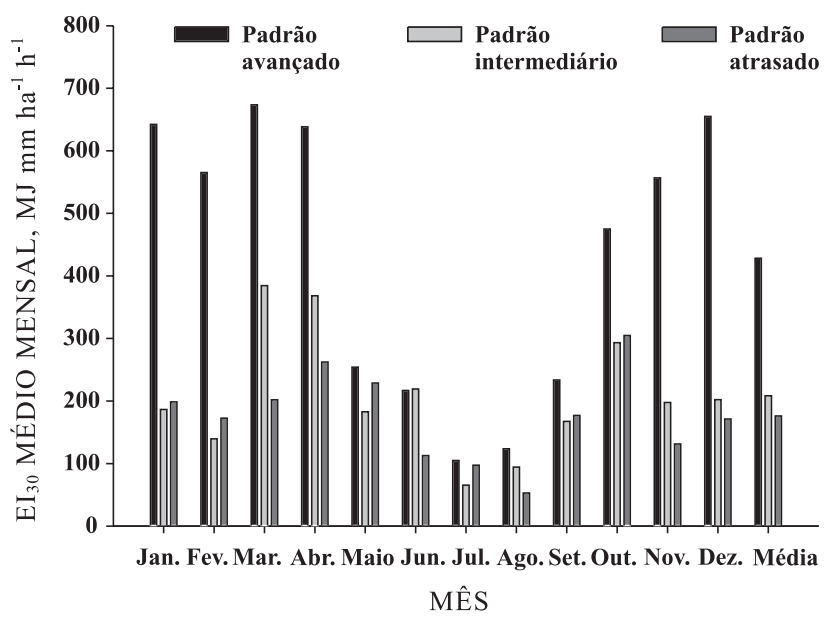

Figura 6. Distribuição da erosividade média mensal por padrões hidrológicos das chuvas erosivas de São Borja, RS, no período de 1956 a 2003.

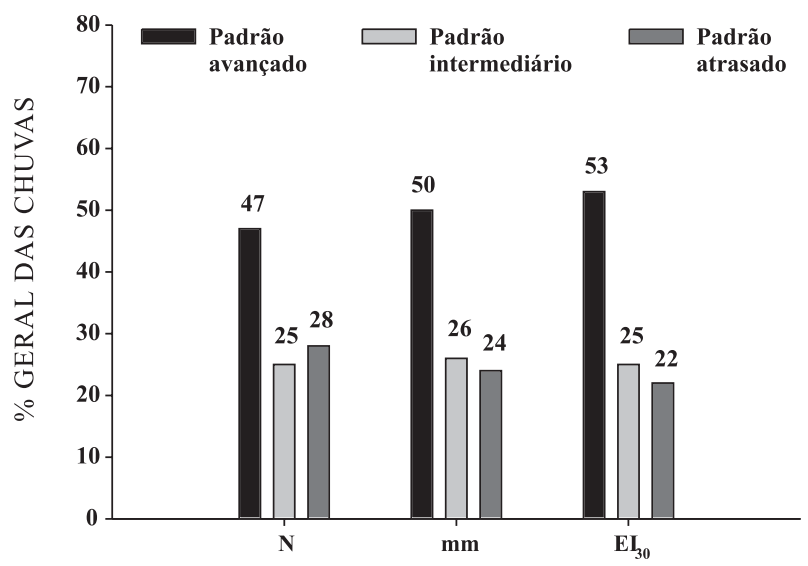

Figura 7. Distribuição percentual média geral do número $(\mathrm{N})$, quantidade $(\mathrm{mm})$ e erosividade $\left(\mathrm{EI}_{30}\right)$ das chuvas de São Borja, RS, por padrões hidrológicos, no período de 1956 a 2003. 


\section{CONCLUSÕES}

1. O valor médio anual do fator "R" da Equação Universal de Perdas de Solo foi de 9.751 MJ mm $\mathrm{ha}^{-1} \mathrm{~h}^{-1}$, caracterizando elevado potencial erosivo das chuvas.

2. O período de outubro a abril foi o mais crítico em relação ao potencial erosivo das chuvas, concentrando $76 \%$ da erosividade anual.

3. O padrão hidrológico avançado foi o de maior ocorrência, seguido dos padrões intermediários e atrasados em relação ao número, quantidade média e erosividade média anual das chuvas erosivas, sendo as diferenças menos acentuadas nos meses de inverno.

4. O fator "R" da USLE, para regiões do entorno, com características climáticas semelhantes, pode ser estimado com dados de pluviometria, usando a equação potencial ajustada.

5. A erosividade média anual das chuvas foi de 9.751 MJ mm ha ${ }^{-1} \mathrm{~h}^{-1}$. Espera-se que ocorra pelo menos uma vez a cada 2,2 anos, com probabilidade de $44,9 \%$.

\section{AGRADECIMENTOS}

Aos observadores meteorológicos da estação de São Borja que, com seu trabalho contínuo, incansável e anônimo, possibilitaram a obtenção dos dados de chuva; a FEPAGRO, por ter disponibilizado os pluviogramas da estação agrometeorológica de São Borja; a FAPERGS e ao CNPq por terem disponibilizado bolsas de iniciação científica.

\section{LITERATURA CITADA}

ALBUQUERQUE, A.W.; LOMBARI NETO, F.; SRINIVASAN, V.S. \& CANTANEO, A. Parâmetros erosividade da chuva e da enxurrada correlacionados com as perdas de solo de um solo Bruno Não Cálcico de Sumé-PB. R. Bras. Ci. Solo, 22:743-749, 1998.

BERTOL, I. Avaliação da erosividade da chuva na localidade de Campos Novos (SC) no período de 1981-1990. Pesq. Agropec. Bras., 29:1453-1458, 1994.

BERTOL, I. Índice de erosividade $\left(\mathrm{EI}_{30}\right)$ para Lages (SC) - $1^{\mathrm{a}}$ aproximação. Pesq. Agropec. Bras., 28:515-521, 1993.

CABEDA, M.S.V. Computations of storms EI values. West Lafayette, Purdue University, 1976. 6p. Não Publicado.

CARVALHO, M.P.; LOMBARDI NETO, F.; VASQUES FILHO, J. \& CATÂNEO, A. Correlação entre o índice de erosividade $\mathrm{EI}_{30}$ médio mensal e o coeficiente de chuva do município de Mococa-SP. Científica - R. Agron., 19:17, 1991 .
COLODRO, G.; CARVALHO, M.P.; ROQUE, C.G. \& PRADO, R.M. Erosividade da chuva: distribuição e correlação com a precipitação pluviométrica de Teodoro Sampaio (SP). R. Bras. Ci. Solo, 26:809-818, 2002.

ELLISON, W.D. Soil detachment and transportation. Soil Conserv., 11:179-190, 1946

ELTZ, F.L.F.; MEHL, H.U. \& REICHERT, J.M. Perdas de solo e água em entressulcos em um Argissolo VermelhoAmarelo submetido a quatro padrões de chuva. R. Bras. Ci. Solo, 25:485-493, 2001.

FOSTER, G.R.; McCOOL, D.K.; RENARD, K.G. \& MOLDENHAUER, W.C. Conversion of the universal soil loss equation to SI units. J. Soil Water Conserv., 36:355359, 1981.

HORNER, W.W. \& JENS, S.W. Surface runoff determination from rainfall without using coefficients. Trans. Am. Soc. Civil Eng., 107:1039-1117, 1942.

LOMBARDI NETO, F. Rainfall erosivity - Its distribution and relationship with soil loss at Campinas, Brazil. West Lafayette, Purdue University, 1977. 53p. (Tese de Mestrado)

MARQUES, J.J.G.S.M.; ALVARENGA, R.C.; CURI, N.; SANTANA, D.P. \& SILVA, M.L.N. Índices de erosividade da chuva, perdas de solo e fator erodibilidade para dois solos da região dos cerrados - primeira aproximação. R. Bras. Ci. Solo, 21:427-434, 1997.

MEHL, H.U.; ELTZ, F.L.F.; REICHERT, J.M. \& DIDONÉ, I.A. Caracterização dos padrões de chuva ocorrentes em Santa Maria (RS). R. Bras. Ci. Solo, 25:475-483, 2001.

MELO MARQUES, J.J.G.S.; ALVARENGA, R.C. \& CURI, N. Erosividade das chuvas da região de Sete Lagoas, MG. Pesq. Agropec. Bras., 33:761-768, 1998.

MORAIS, L.F.B.; MUTTI, L.S.M. \& ELTZ, F.L.F. Índices de erosividade correlacionados com perdas de solo no Rio Grande do Sul. R. Bras. Ci. Solo, 25:485-493, 1988.

MORAIS, L.F.B.; SILVA, V.; NASCHENVENG, T.M.C.; HARDOIN, P.C.; ALMEIDA, J.E.L.; WEBER, O.L.S.; BOEL, E. \& DURIGON, E. Índice $\mathrm{EI}_{30}$ e sua relação com o coeficiente de chuva do sudoeste do Mato Grosso. R. Bras. Ci. Solo, 15:339-344, 1991.

PEÑALVA BAZZANO, M.G.; ELTZ, F.L.F. \& CASSOL, E.A. Erosividade, coeficiente de chuva, padrões e período de retorno das chuvas de Quarai, RS. R. Bras. Ci. Solo, 31:1205-1217, 2007.

RIO GRANDE DO SUL. Secretaria da Agricultura e Abastecimento; Centro Nacional de Pesquisa de Trigo. Macrozoneamento agroecológico e econômico do Estado do Rio Grande do Sul. Porto Alegre, 1994. 2v.

ROQUE, C.G.; CARVALHO, M.P. \& PRADO, R.M. Fator erosividade da chuva de Piraju (SP): distribuição, probabilidade de ocorrência, período de retorno e correlação com o coeficiente de chuva. R. Bras. Ci. Solo, 25:147-156, 2001

RUFINO, R.; BISCAIA, R.C.M. \& MERTEN, G.H. Avaliação do potencial erosivo da chuva do estado do Paraná, através de pluviometria: terceira aproximação. R. Bras. Ci. Solo, 17:439-444, 1993 
SCHWAB, G.O.; FREVERT, R.K.; EDMINSTER, T.W. \& BARNES, K.K. Soil and water conservation engineering. 3.ed. New York, John Wiley \& Sons, 1981. 525p.

SILVA, M.L.N.; FREITAS, P.L.; BLANCANEAUX, P. \& CURI, N. Índices de erosividade das chuvas da região de Goiânia, GO. Pesq. Agropec. Bras., 32:977-985, 1997.

TOMMASELLI, J.T.G.; FREIRE, O. \& CARVALHO, W.A. Erosividade da chuva da região oeste do estado de São Paulo. R. Bras. Agrometeorol., 7:269-276, 1999.
WISCHMEIER, W.H. A rainfall erosion index for a universal soil-loss equation. Soil Sci. Soc. Am. Proc., 23:246-249, 1959.

WISCHMEIER, W.H. Use and misuse of the universal soil loss equation. J. Soil Water Conserv., 31:5-9, 1976.

WISCHMEIER, W.H. \& SMITH, D.D. Predicting rainfall erosion losses - A guide to conservation planning. Washington, USDA, 1978. 58p. (Agriculture Handbook, 537) 